\title{
RESEARCH
}

Open Access

\section{Longitudinal association between body mass index and physical activity among adolescents with different parental risk: a parallel latent growth curve modeling approach}

Parisa Naseri ${ }^{1}$, Parisa Amiri ${ }^{1 *}$ (D) Somayeh Momenyan ${ }^{2}$, Farid Zayeri ${ }^{3^{*}}$, Mehrdad Karimi ${ }^{1,4}$ and Fereidoun Azizi ${ }^{5}$

\begin{abstract}
Background: Data available on the association between physical activity (PA) and body mass index (BMI) in different periods of life is controversial. Using a parallel latent growth curve modeling (LGCM) approach, the current study aimed to investigate the influence of daily PA on adolescents' BMI over a 12 year follow-up, taking into account their parental risk.

Method: Participants comprised 1323 adolescents (53.5\% girls), aged 12-18 years who had participated in the baseline phase of Tehran Lipid and Glucose Study (TLGS) (2001-2003), and were followed for an average period of 12 years. Physical activity, including leisure time and occupational activities, was assessed using the reliable and validated Iranian version of the Modifiable Activity Questionnaire (MAQ). Weight and height were objectively measured in order to calculateBMI.Atwo-step cluster analysis was conducted to classify parents into two high- and low-risk clusters. Parallel LGCM was fitted to estimate cross-sectional, prospective and parallel associations, which assessed the longitudinal association between simultaneous changes in PA and BMI during the study period. Analyses were stratified by gender and parental clusters.

(Continued on next page)
\end{abstract}

\footnotetext{
* Correspondence: amiri@endocrine.ac.ir; fzayeri@gmail.com

${ }^{1}$ Research Center for Social Determinants of Health, Research Institute for Endocrine Sciences, Shahid Beheshti University of Medical Sciences, Tehran,

Iran

${ }^{3}$ Proteomics Research Center and Department of Biostatistics, School of Allied Medical Sciences, Shahid Beheshti University of Medical Sciences, Tehran, Iran

Full list of author information is available at the end of the article
}

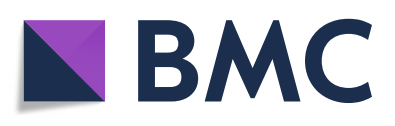

(- The Author(s). 2020 Open Access This article is licensed under a Creative Commons Attribution 4.0 International License, which permits use, sharing, adaptation, distribution and reproduction in any medium or format, as long as you give appropriate credit to the original author(s) and the source, provide a link to the Creative Commons licence, and indicate if changes were made. The images or other third party material in this article are included in the article's Creative Commons licence, unless indicated otherwise in a credit line to the material. If material is not included in the article's Creative Commons licence and your intended use is not permitted by statutory regulation or exceeds the permitted use, you will need to obtain permission directly from the copyright holder. To view a copy of this licence, visit http://creativecommons.org/licenses/by/4.0/. The Creative Commons Public Domain Dedication waiver (http://creativecommons.org/publicdomain/zero/1.0/) applies to the data made available in this article, unless otherwise stated in a credit line to the data. 
(Continued from previous page)

Results: A rising trend of BMl per 3 years was observed in boys $1.39 \mathrm{~kg} \cdot \mathrm{m}^{2}(95 \% \mathrm{Cl} ; 1.32,1.48)$ and girls 0.9 $\mathrm{kg} \cdot \mathrm{m}^{2}(95 \% \mathrm{Cl} ; 0.82,0.98)$, as well as in the low risk $1.11 \mathrm{~kg} \cdot \mathrm{m}^{2}(95 \% \mathrm{Cl} ; 1.03,1.18)$ and high-risk $1.12 \mathrm{~kg} \cdot \mathrm{m}^{2}(95 \% \mathrm{Cl}$; $1.03,1.22)$ clusters. Moreover, a positive prospective association between PA at baseline and BMI change over the 12 year follow-up, was observed in adolescents in the low-risk parental cluster $0.27(95 \% \mathrm{Cl} ; 0.14,0.41)$ indicating that higher levels of PA at baseline may lead to greater BMI in adolescents over time. However, examining longitudinal parallel association between simultaneous changes of PA and BMI per 3 years revealed adverse associations for adolescents in the low-risk parental cluster $-0.07(95 \% \mathrm{Cl} ;-0.13,-0.01)$ and in boys $-0.06(95 \% \mathrm{Cl} ;-0.11,-0.01)$.

Conclusion: Despite a positive prospective association between BMI and PA at baseline, there was a weak inverse parallel association between these variables over time, particularly in boys and adolescents with low parental risk. These findings imply the potential role of other influential factors indetermining adolescents' weight status which need to be considered in the future plannings.

Keywords: BMI, Physical activity, Parental clusters, Parallel latent growth curve modeling

\section{Background}

Obesity is a chronic, often progressive disorder whichis strongly related to type 2 diabetes, hypertension, and cardiovascular diseases (CVDs) [1]. Many developed and developing countries are affected by this public health problem and a large body of evidence exists on the growing trend in mean body mass index (BMI) [2], and the prevalence of obesity and overweight worldwide [3]. Global statistics show that the prevalence of obesity and overweight increased in adolescents boys from 8.1 to $12.9 \%$ and in girls from 8.4 to $13.4 \%$ during $1980-2013$ [4]. Iran as a country located in the Middle East and North Africa (MENA) region reported a high prevalence of obesity in recent decades; the total prevalence of general and abdominal obesity was estimated to be 11.89 and $19.12 \%$ in 2012, respectively [5]. The prevalence of obesity among Iranian children and adolescents is also increasing. In this regard, a meta analysis conducted in Iran, revealed that the prevalence of obesity among adolescents aged 12-18 years increased from $5.55 \%$ in 1995-1999 to 7\% in 2005-2010 [6].

Although a number of studies showed an inverse relationship between PA and adiposity in adults [610], corresponding data for youth is controversial. In this regard, some evidence revealed no significant association between PA levels and excessive weight gain in childhood [11]. Accordingly, studies conducted in Iran indicated that PA levels were not associated with BMI in school-aged children [12, 13]. However, further findings showed that PA is associated with significant changes in BMI among adolescents [14], particulary among teenage boys $[15,16]$. On the other hand, limited longitudinal data on the adult population revealed a parallel association between PA and BMI over time $[17,18]$. To clarify these inconsistencies, longitudinal studies investigating the relationship between PA and weight status with regards to the main influential factors seem necessary.

A broad range of factors including genetic, behavioral, parental and socio-environmental are involved in childhood obesity [19]. Moreover, it seems that family members play a pivotal role in modeling these habits in a shared physical andsocial environment [20]. Accordingly, in a study conducted among Iranian adolescents investigating the association between parental obesity and cardio-metabolic risk factors, researchers demonstrated that the risk of excess weight (OR: 1.30, 95\%CI: 1.17-1.44), obesity (OR: 1.36, 95\%CI: 1.18-1.59) and abdominal obesity (OR: 1.16, 95\%CI: 1.05-1.29) are significantly higher in adolescents whose parents have excess weight, compared to their normal weight counterparts [21]. The effects of different parental factors such as metabolic syndrome and its components, lifestyle behaviors including diet and physical activity as well as educational level on the incidence of non-communicable diseases (NCDs) have also been investigated in previous studies [22$24]$. On the other hand, several studies conducted in Iran and other parts of the world have investigated the potential role of parental characteristics in the weight gain of their children. Results from these studies show a higher prevalence of obesity in youth with lower socioeconomic backgrounds [20, 23, 25, 26]. In our literature review, we found no published literature on the cumulative effects of these factors; according to these results, to account for the cumulative effects of parental characteristics, clustering these factors plays an important role in identifying groups who are at higher risk of chronic diseases [27].

To address the aforementioned gaps and beyond behavioral determinants of childhood obesity, the current study for the first time, aimed to assess the association between PA levels and BMI in adolescents 
with different parental risks. To do this, a two-step cluster analysis for identifying parental risk clusters and age adjusted parallel latent growth curve modeling (LGCM) for estimating cross-sectional, prospective, and parallel associations between these variables will be applied.

\section{Methods}

\section{Study design and population}

This study used data from the TLGS, a populationbased cohort investigation aiming to determine the prevalence of NCD risk factors in a representative sample of residents from district 13 of Tehran. The design of the TLGS included two main components: phase 1, a cross-sectional study of 15,005 participants (women and men, aged $\geq 3$ years), recruited between1999-2001 (baseline) using a multistage cluster sampling technique, with prospective ongoing followup examinations conducted every 3 years for the next 12 years (2004-2016). All socio-demographic, behavioral, anthropometric and clinical data were collected through face-to-face interviews by trained interviewers. Details of the TLGS have previously been published elsewhere [28].

The current longitudinal analysis has been conducted on data from the second to sixth follow-up examinations of the TLGS. A total of 1459 adolescents $(54.4 \%$ girls), aged $12-18$ years, participated in the second phase of the TLGS between 2002 and 2005; of these, 88 and 48 cohort members were excluded due to missing informationon BMI at baseline and incomplete data on parental socio-behavioral and metabolic syndrome (phase 2). Thus the final analytic sample included data on 1323 individuals $(53.5 \%$ girls), followed up for an average period of 12 years with at least 2 follow-up examinations. The participants' age range were $13-24,16-28,19-31$ and 2234 in the third, fourth, fifth and sixth phases respectively.

The study protocol was approved by the ethics committee of the Research Institute for Endocrine Sciences (RIES) of Shahid Beheshti University of Medical Sciences. Written informed consent was obtained from all participants, based on which, information on sex, age, parental clusters, physical activity and BMI were analyzed.

\section{Measurements}

Using a pretested questionnaire, trained interviewers collected data on age, sex and physical activity of adolescents in addition to parental socio-behavioral factors (including job status, level of education, smoking, body weight status and Metabolic equivalent tasks (METs).
Physical activity level, including leisure time and occupational activities, was assessed using a reliable and validated Iranian version of the Modifiable Activity Questionnaire (MAQ) [29]. For adolescents aged $<18$ years, leisure time was used and for those who were aged $\geq 18$ years, both leisure time and occupational activities were taken into account. Participants were asked to report the physical activities in which they had participated during the past 12 months, in addition specifying the frequency and duration for each activity identified. Each activity was weighted by its relative intensity, referred to as MET. One MET is set at $3.5 \mathrm{ml}$ of oxygen consumed per $\mathrm{kg}$ of body weight per minute and represents the resting metabolic rate. For all activity levels, obtained MET was multiplied by the time spent at each level. MET-time from each level was added to total 24h MET- time, representing the average daily level of PA. For analytical purposes, leisure time physical activity (LTPA) values were standardized as z-scores. Moreover, levels of physical activity were defined as low (MET < $600 \mathrm{~min} / \mathrm{wk}$ ), moderate (MET 600-2999 min/wk) and high (MET $\geq 3000 \mathrm{~min} / \mathrm{wk}$ ) [30]. Weight was measured using digital scales, in light clothing and without shoes rounded to the nearest $100 \mathrm{~g}$. Height was measured using a tape meter stadiometer. BMI was calculated as weight in kilograms divided by height in square meters. To remove subjective errors, all measurements were recorded by the same study personnel.

\section{Definition of terms}

High-risk and low-risk parental clusters were identified based on the parents' socio-behavioral characteristics and METs. For this purpose, their education levels were defined as primary, secondary and higher. Job status was categorized into two sub categories of employed and unemployed. Metabolic syndrome in parents, aged $>18$ years was defined based on the Joint Interim Statement (JIS) [31] as the presence of any three of the following five riskfactors: (1) Abdominal obesity with a waist circumference (WC) $\geq 90 \mathrm{~cm}$ for both genders, based on Iranian cut off values [32, 33]; (2) HDL-C $<50 \mathrm{mg} / \mathrm{dL}$ in women and $<40$ in men or receiving medical treatment to reduce HDL-C; (3) elevated TG level $\geq 150 \mathrm{mg} / \mathrm{dL}$ or medical treatment for hypertriglyceridemia; (4) hypertension $\geq 130 \mathrm{mmHg}$ systolic blood pressure or $\geq 85 \mathrm{mmHg}$ diastolicblood pressure) or using anti hypertensive treatment in a patient with a history of hypertension and (5) elevated $\mathrm{FBG} \geq 100 \mathrm{mg} / \mathrm{dL}$ or drug treatment for the condition.

A two-step cluster analysis was conducted to classify parents in the two different classes. Cluster numbers were determined using the Schwartz's Bayesian 
Criterion (BIC) index. Cluster analysis is an exploratory tool applied in order to organize observations or cases into different subgroups of individuals. In this method, the similarity of cases within each cluster is maximized and similarity between groups is minimized. There are a number of clustering procedures including hierarchical, k-means, and two-step cluster analysis. The hierarchical, k-means clustering and two-step procedure cluster analysis are more appropriate for small, moderate and large datasets (1000 cases or more), respectively. In addition, when a mixture of continuous and categorical variables are available, two-step procedure cluster analysis is recommended. In the current study, to detect intrinsic differences between participants, a two-step cluster analysis was used for continuous and categorical variables. For separation of adolescents, we first identified the variables significantly related with BMI and then included these variables in the cluster analysis.

\section{Statistical analysis}

All analyses were gender-specific and have been stratified by parental clusters (low- and high risk). Baseline characteristics of the adolescent participants were summarized as means $\pm \mathrm{SD}$ and frequencies (percentages) for continuous and categorical variables, respectively. Continuous variables were compared between gender and parental clusters using the independent samples T-test.

For descriptive purposes, mean BMI and standardized LTPA from the second phase (2004-2006) to the sixth phase (2014-2016) of the TLGS are illustrated in Figs. 1 and 2 by parental clusters and gender, separately. To assess the linear trend of BMI and standardized LTPA throughout the phases, a marginal model was fitted using the generalized estimating equation (GEE) methodology, separately for each category of parental cluster and gender. In each model, the time effect was reported as $\mathrm{p}$ for trend. In addition, differences in mean BMI and standardized LTPA were both examined over phases across the parental clusters and gender susing the interaction terms: parental clusters $\times$ phase and sex $\times$ phase.

In the analysis process, the longitudinal trajectories of BMI as well as standardized LTPA over the 12year period were investigated using the LGCM, a multivariate statistical method applied within the structural equational modeling (SEM) framework to estimate growth patterns over time. Unconditional LGCM for outcome $y_{t i}$ for individual $i$ at timet is written as follows:

$$
y_{t i}=\lambda_{0 t} \eta_{0 i}+\lambda_{1 t} \eta_{1 i}++\varepsilon_{t i}
$$

where $\eta_{0 i}=v_{0}+z_{0 i}$ and $\eta_{1 i}=v_{1}+z_{1 i}$. The outcome $\left(y_{t i}\right)$ can be predicted by two latent growth factors, $\eta_{0 i}$ (i.e., intercept) and $\eta_{1 i}$ (i.e., slope) and residual $\varepsilon_{t i}$, in which $v_{0}$ and $v_{1}$ are latent means and $\mathrm{z}_{0 i}$ and $\mathrm{z}_{1 i}$ are individual deviations away from those means. In this analysis, a conditional LGCM for each outcome variable (BMI and standardized LTPA) was fitted and the latent growth factors of models were predicted using the baseline age covariate. To estimate the latent growth model parameters (intercept and slope), the factor loadings, $\lambda_{0 t}$ and $\lambda_{1 t}$, were constrained to [1] and $[0,1,2,3,4]$, respectively.

Finally, a parallel LGCM was fitted to predict the latent growth factors of BMI, using the latent growth factors of the standardized LTPA (Fig. 3). This approach allows the linear relationship between PA and BMI to vary between individuals in both slope and intercept. In this model, some specific effects were assessed including: 1) a cross-sectional association between BMI and standardized LTPA at baseline; 2) a

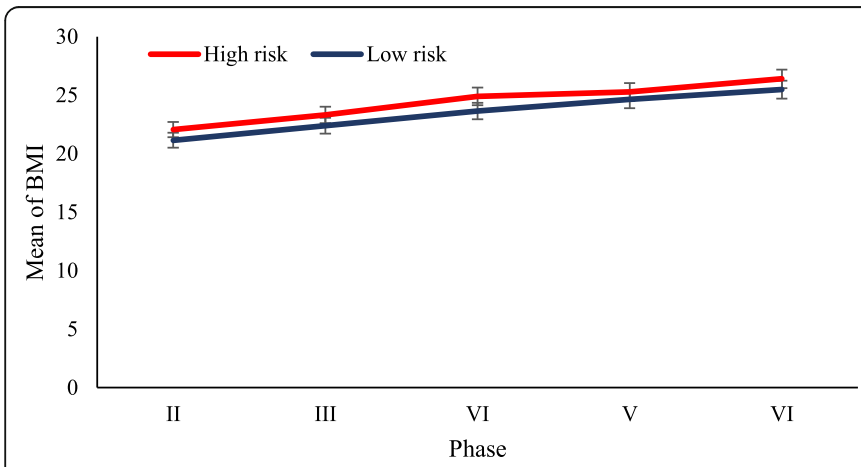

(a)

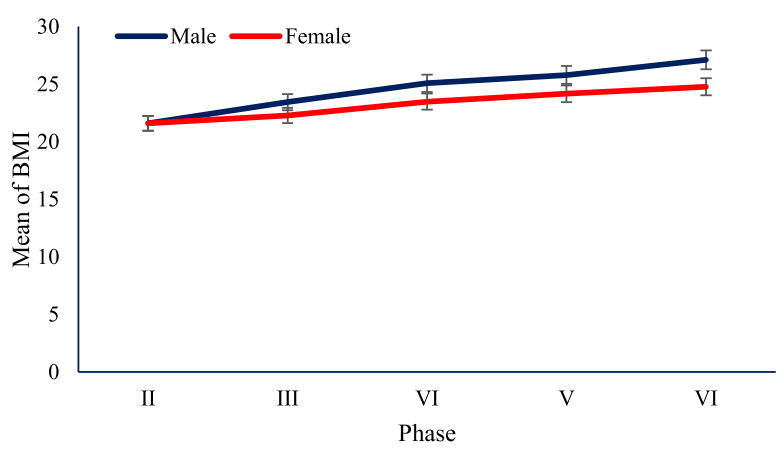

(b)

Fig. 1 Trend of BMI of adolescents, aged 12-18years: TLGS II- VI. a Based on parental clusters; P-interaction for parental clusters/year= 0.59. b Based on sex strata. P-interaction for sex/year< 0.001; Error bars shows standard error 


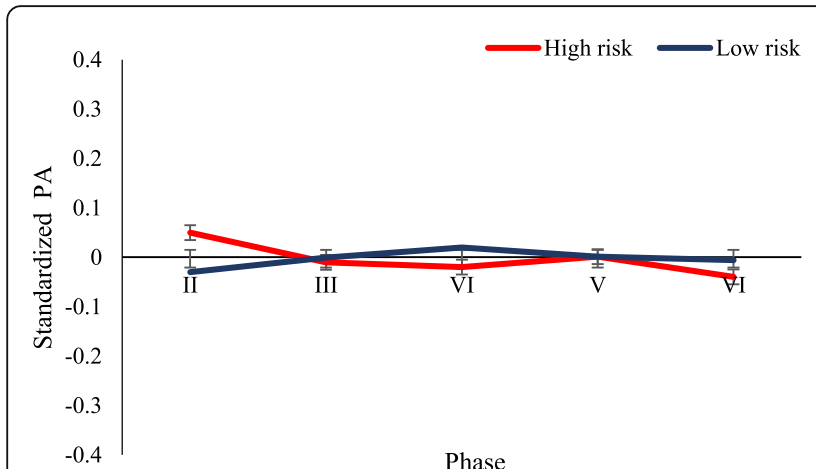

(a)

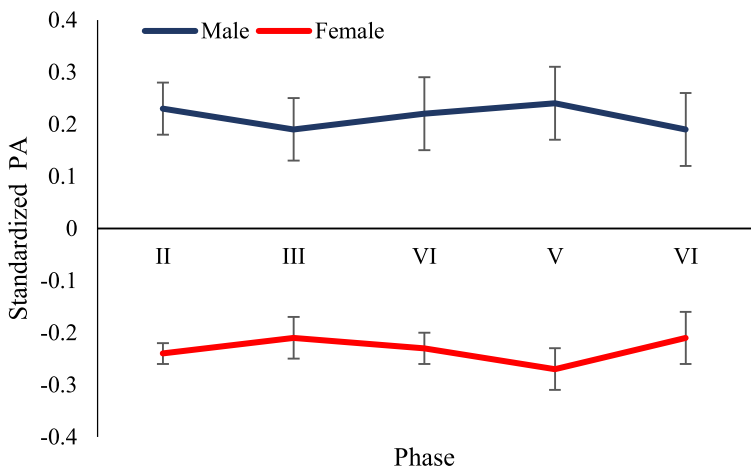

(b)

Fig. 2 Trend of standardized physical activity (MET-minutes per week) of adolescents, aged 12-18 years: TLGS II- VI. a Based on parental clusters strata. P-interaction for parental clusters/year $=0.51$. b Based on sex strata. P-interaction for sex/year $=0.24$; Error bars shows standard error

prospective association between baseline standardized LTPA and the change in BMI, and 3) parallel association between changes in standardized LTPA and change in BMI over the 12-year period.

The model goodness of fit was assessed using the comparative fit index (CFI), Tucker-Lewis index (TLI), and root mean square error of approximation (RMSEA). As atisfactory fit was accepted when CFI $\geq$
0.9, TLI $\geq 0.9$, and RMSEA $\leq 0.08$ [34]. The Mplus v7.2 (MutheÂn\&MutheÂn, LA, CA), and IBM SPSS Statistics version 22 were used for data analysis and $p$ value $<0.05$ was considered statistically significant.

\section{Results}

A total number of 1323 adolescents, aged $12-18$ years on whom we had complete information on parental

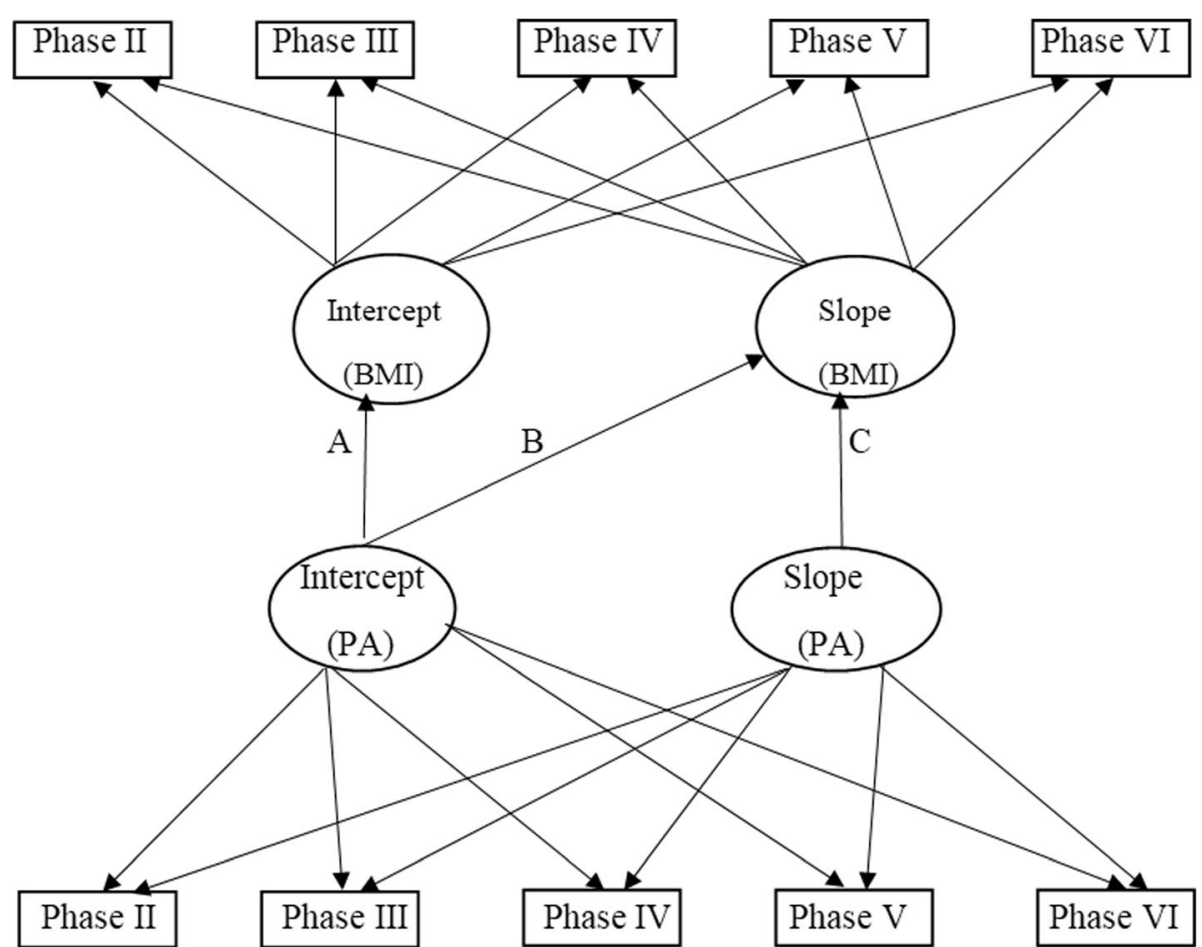

Fig. 3 A schematic diagram depicting the parallel latent growth curve model; A: paths examining the cross-sectional associations of baseline PA with baseline BMI (Intercept (PA) $\rightarrow$ Intercept (BMI).B: paths examining the prospective associations of baseline PA with change in BMI (Intercept $(\mathrm{PA}) \rightarrow$ Slope $(\mathrm{BMI}))$. C: parallel associations of changes in PA with change in BMI (Slope $(\mathrm{PA}) \rightarrow$ Slope (BMI)) 
factors and BMI at baseline, were included in the cluster analysis. Three different socio-behavioral factors of parents (age, educational level, occupation) as well as METs, and BMI status were considered for parental cluster analysis. The most and the least important factors were maternal METs (with an importance value of 1) and paternal METs, respectively (Fig. 4- Appendix).

Results of the cluster analysis revealed two distinct parental clusters, referred to as low- and high-risk families. Table 4 (see Appendix) compares parental socio-behavioral status and MetS in these clusters. All parental socio-behavioral variables and METs were statistically significant between the two clusters $(p<$ 0.001) which indicated difference among individuals in the low-and high-risk parental clusters regarding the aforementioned variables. However, we found no significant difference between the two groups in terms of the least important factor, i.e. paternal METs. In the high risk cluster, most parents had primary level education ( $74.8 \%$ of mothers and $68 \%$ of fathers). Moreover, the mean of maternal age in the high-risk cluster was higher than that of mothers in the lowrisk cluster (45.41 versus 39.39 years) and the mean of paternal age was 44.55 and 51.88 years in the highand low-risk parental clusters, respectively. In the low- and high-risk clusters, most mothers were unemployed ( 87.7 and $97.9 \%$, respectively) while the corresponding rates for fathers were 7 and $29.9 \%$, respectively. Regarding body weight status, 71.1 and $15.6 \%$ of mothers were obese in high- and low-risk parental clusters, respectively.

Baseline characteristics of adolescent girls and boys according to their parental clusters are presented in Table 1; the mean age of the participants was 14.65 $(\mathrm{SD}=1.85)$ and 15.24 ( $\mathrm{SD}=1.80)$ for low- and highrisk parental clusters, respectively. In addition, mean standardized LTPA was $-0.03 \quad(\mathrm{SD}=0.93)$ and 0.05 $(\mathrm{SD}=1.09)$ in the low- and high-risk parental clusters, respectively. Mean BMI for participants in the highrisk parental cluster was higher than in the low-risk one, a difference that was statistically significant (22.05 versus $21.14, P<0.05)$. Sex-specific details are also presented in Table 1. Moreover, distribution of physical activity levels at basline is shown in Table 5 of Appendix. Mean BMI and standardized LTPA for parental clusters and gender categories duringthe TLGS phases are illustrated in Figs. 1 and 2, respectively. As shown, there was a significant rising trend of mean BMI among both parental clusters and gender groups $(\underline{P}<0.05)$, however no significant trend for standardized LTPA was observed in the low-risk (0.008 (95\% CI; $-0.025,0.04) ; P=0.637)$ and high-risk parental clusters $(-0.021(95 \% \mathrm{CI} ;-0.056,0.014)$; $P=0.246)$, or in boys $(-0.004 \quad(95 \% \mathrm{CI} ;-0.042$, $0.034) ; P=0.845)$ and girls $(-0.001$ (95\% CI;-0.029, $0.027) ; P=0.937)$. Neither was the interaction of parental clusters and phases significant in BMI nor in standardized LTPA. In addition, the interaction of sex and phases was statistically significant for BMI (-0.54 (95\% CI; $-0.68,-0.41) ; P<0.001)$, which showed differences in BMI changes between males and females over time, while this was not significant for standardized LTPA.

Model fit indices based on parental clusters, gender and total population are presented in Table 2; LGCMs were fitted to each outcome variable (BMI and standardized LTPA) and then a parallel LGCM was fitted to these variables concurrently. Model fit indices showed that the fitted models were acceptable across parental clusters, genders and the total population. After adjusting for baseline age, longitudinal changes in BMI and standardized LTPA were well identified over the study period (RMSEA $\leq .08$, CFI $\geq .90$, and $\mathrm{TLI} \geq .90$ ).

Table 3 presented parameter estimates for described LGCMs and the parallel LGCM. The latent growth parameters estimated from the LGCM of BMI demonstrated significant increases in BMI per 3 years (estimated slopes for all models) for both parental clusters; $1.11 \mathrm{~kg} \cdot \mathrm{m}^{2} \quad(95 \% \mathrm{CI} ; 1.03,1.18)$ and 1.12 kg. $\mathrm{m}^{2}(95 \% \mathrm{CI} ; 1.03,1.22)$ in the low- and high-risk parental clusters, respectively. These values were 1.39 kg.m ${ }^{2}(95 \%$ CI; $1.32,1.48)$ in boys and $0.9 \mathrm{~kg} \cdot \mathrm{m}^{2}(95 \%$ $\mathrm{CI} ; 0.82,0.98)$ in girls and $1.12 \mathrm{~kg} . \mathrm{m}^{2}(95 \% \mathrm{CI} ; 1.06$, 1.18) for the total population. However, the estimated

Table 1 Baseline characteristics of study sample by gender and parental clusters

\begin{tabular}{|c|c|c|c|c|c|c|}
\hline & \multicolumn{3}{|l|}{ Parental clusters } & \multicolumn{3}{|l|}{ Sex } \\
\hline & Low risk $(n=748)$ & High risk $(n=575)$ & $P$-value & Male $(n=623)$ & Female $(n=700)$ & $P$-value \\
\hline$\overline{\text { Age (year) }}$ & $14.65 \pm 1.85$ & $15.24 \pm 1.80$ & $<0.001$ & $14.87 \pm 1.87$ & $14.94 \pm 1.84$ & 0.46 \\
\hline Standardized Physical activity & $-0.03 \pm 0.93$ & $0.050 .05 \pm 1.09$ & 0.217 & $0.23 \pm 1.19$ & $-0.24 \pm 0.66$ & $<0.001$ \\
\hline Physical activity & $1357.9210 \pm 1645.86$ & $1503.8921 \pm 1941.08$ & 0.217 & $1821.20 \pm 2113.82$ & $984.76 \pm 1179.00$ & $<0.001$ \\
\hline BMI & $21.14 \pm 4.04$ & $22.05 \pm 4.33$ & $<0.001$ & $21.53 \pm 4.47$ & $21.54 \pm 3.93$ & 0.97 \\
\hline
\end{tabular}


Table 2 Model fit indices for the latent growth curve models by parental clusters and gender

\begin{tabular}{|c|c|c|c|c|c|c|c|c|c|c|c|c|}
\hline & \multicolumn{4}{|c|}{ Outcome: BMI } & \multicolumn{4}{|c|}{ Outcome: PA } & \multicolumn{4}{|c|}{ Parallel LGCM } \\
\hline & $\overline{x^{2} / d f}$ & RMSEA $(90 \%$ Cl) & $\mathrm{CFI}$ & $\overline{T L I}$ & $\overline{x^{2} / d f}$ & RMSEA $(90 \% \mathrm{Cl})$ & $\mathrm{CFI}$ & $\overline{T L I}$ & $\overline{x^{2} / d f}$ & RMSEA (90\% Cl) & $\mathrm{CFI}$ & $\overline{\mathrm{TLI}}$ \\
\hline Low risk & $73.46 / 10$ & $0.08(0.07-0.10)$ & 0.96 & 0.96 & $32.70 / 10$ & $0.05(0.03-0.07)$ & 0.77 & 0.77 & $155.99 / 41$ & $0.059(0.050-0.07)$ & 0.95 & 0.94 \\
\hline Haigh risk & $28.07 / 10$ & $0.05(0.03-0.07)$ & 0.95 & 0.95 & $34.85 / 10$ & $0.06(0.04-0.09)$ & 0.60 & 0.60 & $87.51 / 41$ & $0.04(0.03-0.05)$ & 0.95 & 0.94 \\
\hline Male & $46.55 / 10$ & $0.07(0.05-0.09)$ & 0.92 & 0.92 & $27.54 / 10$ & $0.05(0.03-0.07)$ & 0.74 & 0.74 & $118.59 / 41$ & $0.053(0.04-0.06)$ & 0.93 & 0.92 \\
\hline Female & $37.52 / 10$ & $0.05(0.04-0.08)$ & 0.97 & 0.97 & $11.76 / 10$ & $0.01(0.00-0.04)$ & 0.96 & 0.96 & $90.79 / 41$ & $0.03(0.02-0.05)$ & 0.97 & 0.97 \\
\hline All & $28.07 / 10$ & $0.05(0.03-0.07)$ & 0.95 & 0.95 & $34.27 / 10$ & $0.044(0.02-0.06)$ & 0.80 & 0.81 & $135.48 / 41$ & $0.041(0.03-0.05)$ & 0.96 & 0.95 \\
\hline
\end{tabular}

slope for standardized LTPA across the five TLGS phases was not significant in the above-mentioned grouping variables. Moreover, there was no significant covariance between latent growth parameters of BMI and standardized LTPA based on parental clusters, gender groups and total population, indicating that there was no linear relationship between baseline BMI (standardized LTPA) and per 3 years changes in BMI (standardized LTPA) in these groups. Regarding the results of the parallel LGCM, baseline level of standardized LTPA was not significantly associated with BMI at baseline (effect of baseline standardized LTPA on baseline BMI) across parental clusters, gender strata or the total population. In other words, there was no significant cross-sectional association between LTPA and BMI at baseline. Meanwhile, a significant positive prospective association between baseline LTPA and per 3 years changes in BMI over the 12year period (effect of baseline standardized LTPA on slope BMI) was observed in the low-risk parental cluster 0.27 (95\% CI; 0.14, 0.41) and total population 0.18 (95\% CI; 0.08, 0.28). After increasing LTPA at baseline, BMI increased by 0.27 in the low-risk parental cluster and 0.18 in the total population over time. We also found no significant associations in gender groups or in the high-risk parental cluster. Finally, a significant parallel association between changes in standardized LTPA and changes in BMI per 3 years (effect of standardized LTPA slope on BMI slope) was observed in the low-risk parental cluster -0.07 (95\% $\mathrm{CI} ;-0.13,-0.01)$, boys -0.06 (95\% CI; $-0.11,-0.01)$ and total population - $0.05(95 \% \mathrm{CI} ;-0.09,-0.01)$. In other words, increasing LTPA over time led to decreasing BMI during the study period in the low-risk parental cluster as well as the total population.

\section{Discussion}

This study aimed to examine cross-sectional and longitudinal associations between PA and BMI among TLGS adolescents with different parental risk. While there was no relationship between adolescents' PA and BMI at baseline, our findings indicated a significant longitudinal association between these two variables in the low-risk cluster. Considering parallel associations between simultaneous changes in PA and BMI over time, the current findings revealed a positive effect of PA on decreasing BMI among male adolescents and those in the low-risk cluster.

In the current study, parental body weight status, occupation, education, age as well as METs in mothers, were the main discriminating variables at baseline between low- and high-risk parental clusters. Parents play a pivotal role in shaping offspring habits within a shared physical and social environment which could affect their lifestyle during childhood [20, 35]. Although the influence of parental role-modeling will decrease over time, it can be reasonable to assume that the effect7 will remain until adulthood. In the current study, on average both parents in highrisk clusters were older, less educated and more overweight/obese than their counterparts in the low-risk cluster, a finding that was consistent with those of previous studies $[23,24,36]$. Few studies have focused on the synergistic effects of parental factors on the BMI and lifestyle behaviors of children including PA, which makes it difficult to compare current results with those previously documented. Considering this limitation, current results regarding no significant difference in PA level between low- and high-risk parental clusters is in line with previous reports that also revealed no relationship between parents'socioeconomic status (SES) and PA levels in their offspring $[37,38]$. Among SES factors, parents educational levels (unlike job status) were rarely associated with the PA of their children [39]. However, other findings from Iran also report no significant correlation between children's PA level and parents'education as well as job status [40]. Instead of PA, our study indicated significantly higher BMI in adolescents classified in the high-risk parental cluster. A study conducted among Swedish children showed an inverse association between parental education and BMI [41]. In addition, other studies from Iran showed that children from lower SES families are estimated to be at significantly higher risk of becoming overweight/obese, compared to children whose parents also had higher 


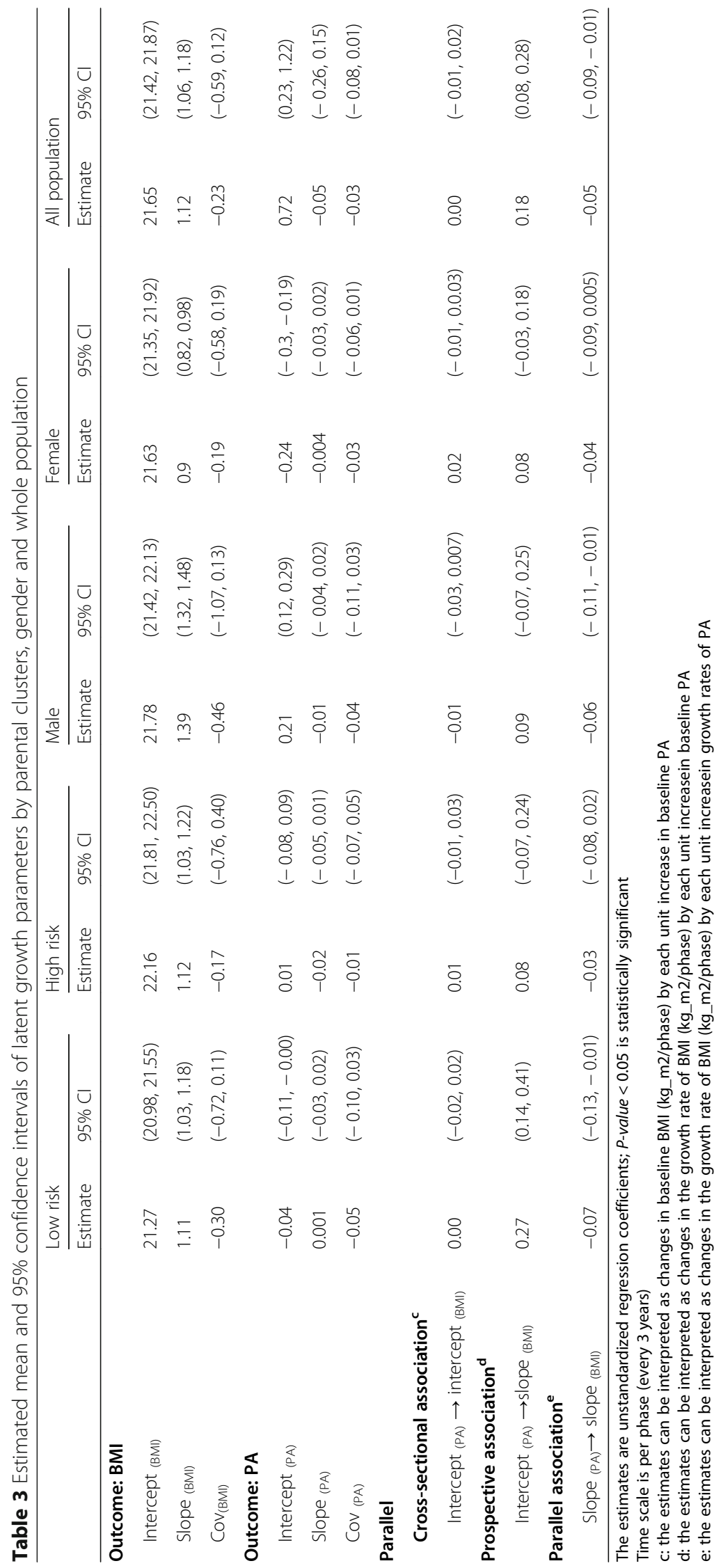


mean BMI [21, 42-44]. In regard to the synergistic effects of parental factors, a study revealed higher risk for incidence of overweight in the high-risk cluster compared with those in the low-risk cluster [45].

In the current study, although boys were more active than girls, both genders had inadequate levels of PA. Studies across the world show different patterns of PA in girls and boys. While more sedentary recreational behaviors have been observed in boys, they were still more physically active than girls $[46,47]$. Consistent with the current findings, other studies from Iran indicate higher levels of PA in boys than girls [12, 48-50]. In addition, the current findings showed no significant difference in mean BMI between girls and boys. These results are similar to those of a national survey of Iranian adolescents reporting that mean BMI in girls was higher than boys, this difference however was not statistically significant [51].

Based on our findings, there was no significant crosssectional association between PA and BMI at baseline. This result may be related to nature of PA as a lifestyle component, it could be changed during life course [52, 53]. Accordingly, the effect of this behavior is revealed during the follow-up period rather than at baseline. Cross-sectional data from Iran and other countries showan inverse relationship between BMI and PA in adolescents [7, 54], however, another study showed no cross-sectional association between time spent on physical and sedentary activities with BMI-for-age among high school students in Tehran [12].

In the present study, significant longitudinal and parallel associations between adolescents' BMI and PA were observed in the low-risk parental cluster, indicating that the more children are active at baseline and during follow-up years, the lower the increase in mean BMI over the study period. The current findings are in agreement with a previous longitudinal study from Europe indicating that higher levels of total PA and moderate-to-vigorous PA (MVPA) were associated with lower BMI in children over a 5 year follow-up [55]. In the current study, there were no significant longitudinal and parallel associations between adolescents' BMI and PA in the high-risk parental cluster, which can be related to the effect of other variables such as adolescents' dietary patterns, genetic and metabolic backgrounds. The association between parental obesity and metabolic disorders andoverweight in children have been well-documented $[56,57]$. In this regard a study showed that schoolchildren from families with at least one parent with metabolic disorder had significantly higher BMI at baseline measurement and faster BMI progression during their growth period [58]. Accordingly, another study indicated that half of the offspring of mothers with type 2 diabetes weighed higher than the 90th percentile for their age population [59]. In addition to metabolic backgrounds, the important effectof children's genetic backgrounds [60] as well as socio-behavioral factors including dietary habits and socio-economic status (SES) on adolescents' weight status have been determined $[42,43]$. In this regard previous studies revealed that low SES families mainly charachterized by lower income and education have little access to healthy foods and are more likely to consume high-calorie, low nutrient food stuffs [61, 62]. All these factors could modify the effect of PA levels on adolescent weight status inthe high-risk parental cluster.

The strength of the current study, is its consideration of parental data and its synergistic effect as an important factor in childhood obesity. Compared to previous studies, its 12 year follow-up could also be considered as a strength of the present study from Iran, a region of the Middle East. From an analytical point of view, our study applied a precise longitudinal method. Previous studies only considered changes of outcome variables between baseline and end of follow-up period while this analytical approach modeled observations in each phase of the study. In addition, all parameters related to crosssectional, prospective, and parallel associations among variables were estimated. However, the results were affected by some limitations including unavailable data on adolescents' diet as an important modifier. Moreover, it has been well-established that there may be biological and genetic factors that contribute to the variability of physical activity on body weight regulation which require further investigation $[63,64]$. Furthermore, subjective methods were used to measure PA which could affect the accuracy of data by creating recall bias. Last but not least, it would have been useful to assess the association between PA and BMI, considering different body weight status at baseline to design related preventive programs and interventions.

\section{Conclusions}

Our study showed a weak inverse parallel association between PA and BMI in adolescent boys and those with low-risk parents over the follow-up period. Similar results were not observed in adolescents with high parental risk and in girls. Current findings imply the pivotal role of other influential factors including metabolic and genetic backgrounds as well as SES and dietary patterns to determine adolescents' weight status; these findings need to be considered in future plannings for weight management in the early years of life. 


\section{Appendix}

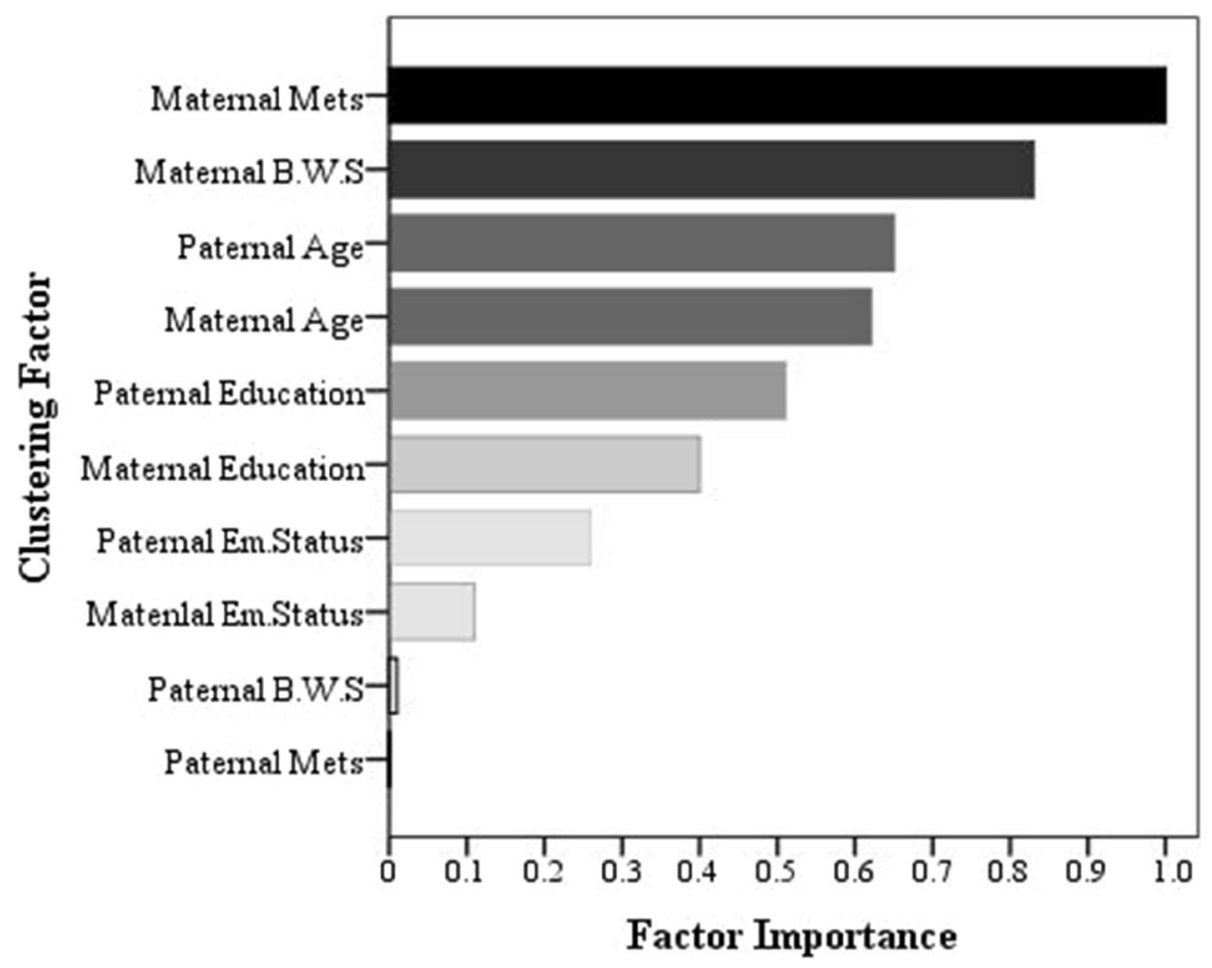

Fig. 4 The importance of variables included in the cluster analysis 
Table 4 Descriptive statistics of parents' socio-behavioral and MetS status in two clusters

\begin{tabular}{|c|c|c|c|}
\hline & \multicolumn{3}{|l|}{ Parental clusters } \\
\hline & Low risk $(n=748)$ & High risk $(n=575)$ & $P$-value \\
\hline \multicolumn{4}{|c|}{ Mothers' characteristics } \\
\hline Age (years) & $39.39 \pm 4.94$ & $45.41 \pm 6.77$ & $<0.001$ \\
\hline Level of education & & & $<0.001$ \\
\hline Primary & $271(36.2 \%)$ & $430(74.8 \%)$ & \\
\hline Secondary & $410(54.8 \%)$ & $137(23.8 \%)$ & \\
\hline Higher & $67(9 \%)$ & $8(1.4 \%)$ & \\
\hline Occupation & & & $<0.001$ \\
\hline Employed & $91(12.2 \%)$ & $12(2.1 \%)$ & \\
\hline Unemployed & $657(87.7 \%)$ & $563(97.9 \%)$ & \\
\hline MetS status & & & $<0.001$ \\
\hline Yes & $133(17.8 \%)$ & 447 (77.7\%) & \\
\hline No & 615 (82.2\%) & $128(22.3 \%)$ & \\
\hline Body weight status & & & $<0.001$ \\
\hline Normal & $186(24.9 \%)$ & $27(4.7 \%)$ & \\
\hline Overweight & $445(59.5 \%)$ & $139(24.2 \%)$ & \\
\hline Obese & $117(15.6 \%)$ & 409 (71.1\%) & \\
\hline \multicolumn{4}{|l|}{ Fathers' characteristics } \\
\hline Age (years) & $44.55 \pm 5.76$ & $51.88 \pm 8.15$ & $<0.001$ \\
\hline Level of education & & & $<0.001$ \\
\hline Primary & $179(23.9 \%)$ & $391(68.0 \%)$ & \\
\hline Secondary & $395(52.8 \%)$ & $114(19.8 \%)$ & \\
\hline Higher & $174(23.3 \%)$ & $70(12.2 \%)$ & \\
\hline Occupation & & & $<0.001$ \\
\hline Employed & 696 (93\%) & $403(70.1 \%)$ & \\
\hline Unemployed & $52(7 \%)$ & 172 (29.9\%) & \\
\hline MetS status & & & 0.169 \\
\hline Yes & $441(59 \%)$ & $323(56.2 \%)$ & \\
\hline No & $307(41 \%)$ & $252(43.8 \%)$ & \\
\hline Body weight status & & & 0.008 \\
\hline Normal & $223(29.8 \%)$ & 207 (36\%) & \\
\hline Overweight & $343(45.9 \%)$ & 264 (45.9\%) & \\
\hline Obese & 182 (24.3\%) & 104 (18.1\%) & \\
\hline
\end{tabular}

Table 5 Distribution of levels of physical activity based on parental clusters and gender

\begin{tabular}{|c|c|c|c|c|c|c|}
\hline & \multicolumn{3}{|c|}{ Parental clusters } & \multicolumn{3}{|l|}{ Sex } \\
\hline & Low risk n(\%) & High risk n(\%) & $P$-value & Male n(\%) & Female $n(\%)$ & $P$-value \\
\hline \multicolumn{7}{|c|}{ Physical activity levels } \\
\hline Low & $428(57.2)$ & $330(57.4)$ & & $269(43.2)$ & $489(69.9)$ & \\
\hline Moderate & $267(35.7)$ & $191(33.2)$ & 0.25 & $274(44)$ & $184(26.3)$ & $<0.001$ \\
\hline High & $53(7.1)$ & $54(9.4)$ & & $80(12.8)$ & $27(3.9)$ & \\
\hline
\end{tabular}




\section{Abbreviations}

SES: Socioeconomic status; BMl: Body mass index; PA: Physical activity; LGCM: Latent growth curve modeling; TLGS: Tehran lipid and glucose study; MAQ: Modifiable Activity Questionnaire; CVDs: Cardiovascular diseases; MENA: Middle East and North Africa; NCD: Non-communicable disease; MetS: Metabolic syndrome; MET: Metabolic equivalent; LTPA: Leisure time physical activity; JIS: The Joint Interim Statement; WC: Waist circumference; BIC: Bayesian criterion; GEE: The generalized estimating equation; SEM: The structural equational modeling; CFI: The comparative fit index; TLI: TuckerLewis index; RMSEA: Root mean square error of approximation

\section{Acknowledgements}

Authors would like to express their appreciation to all participants who made this study possible and wish to acknowledge Ms. Niloofar Shiva for critical editing of English grammar and syntax of the manuscript.

\section{Authors' contributions}

PN, PA and SM designed the study. MK participated in acquisition of data. FZ, MK and PN carried out the statistical analysis. PA, FZ, SM and PN contributed to interpretation of data. PN, PA and FZ drafted the manuscript. PA, FZ and FA supervised the manuscript. All authors read and approved the final manuscript.

\section{Funding}

There are no funding resources for this research.

\section{Availability of data and materials}

The datasets used and/or analyzed during the current study are available from the corresponding authors on reasonable request.

\section{Ethics approval and consent to participate}

This study was approved by the research ethics committee of the Research Institute for Endocrine Sciences (RIES), Shahid Beheshti University of Medical Sciences, Tehran, Iran (the ethics approval code:

IR.SBMU.ENDOCRINE.REC.1397.095). Prior to data collection, both children and parents were informed about the study procedure and its aims and if the child and parent agreed to participate in the study, parents were asked to sign a written consent form.

\section{Consent for publication}

Not applicable.

\section{Competing interests}

The authors declare that they have no competing interests.

\section{Author details}

${ }^{1}$ Research Center for Social Determinants of Health, Research Institute for Endocrine Sciences, Shahid Beheshti University of Medical Sciences, Tehran, Iran. ${ }^{2}$ Department of Biostatistics and Epidemiology, Qom University of Medical Sciences, Qom, Iran. ${ }^{3}$ Proteomics Research Center and Department of Biostatistics, School of Allied Medical Sciences, Shahid Beheshti University of Medical Sciences, Tehran, Iran. ${ }^{4}$ Department of Epidemiology and Biostatistics, School of Public Health, Tehran University of Medical Sciences, Tehran, Iran. ${ }^{5}$ Endocrine Research Center, Research Institute for Endocrine Sciences, Shahid Beheshti University of Medical Sciences, Tehran, Iran.

\section{Received: 3 November 2019 Accepted: 27 April 2020}

Published online: 11 May 2020

\section{References}

1. Bastien M, Poirier P, Lemieux I, Després J-P. Overview of epidemiology and contribution of obesity to cardiovascular disease. Prog Cardiovasc Dis. 2014; 56(4):369-81.

2. Finucane MM, Stevens GA, Cowan MJ, Danaei G, Lin JK, Paciorek CJ, et al. National, regional, and global trends in body-mass index since 1980: systematic analysis of health examination surveys and epidemiological studies with 960 country-years and 9. 1 million participants. Lancet. 2011; 377(9765):557-67.

3. Stevens GA, Singh GM, Lu Y, Danaei G, Lin JK, Finucane MM, et al. National, regional, and global trends in adult overweight and obesity prevalences. Popul Health Metrics. 2012;10(1):22.
4. Ng M, Fleming T, Robinson M, Thomson B, Graetz N, Margono C, et al. Global, regional, and national prevalence of overweight and obesity in children and adults during 1980-2013: a systematic analysis for the global burden of disease study 2013. Lancet. 2014;384(9945):766-81.

5. Esmaili H, Bahreynian M, Qorbani M, Motlagh ME, Ardalan G, Heshmat R, et al. Prevalence of general and abdominal obesity in a nationally representative sample of Iranian children and adolescents: the CASPIAN-IV study. Iran J Pediatr. 2015;25(3):e401.

6. Jakicic JM, Jaramillo SA, Balasubramanyam A, Bancroft B, Curtis JM, Mathews $A$, et al. Effect of a lifestyle intervention on change in cardiorespiratory fitness in adults with type 2 diabetes: results from the look AHEAD study. Int J Obes. 2009;33:305.

7. Fan JX, Brown BB, Hanson H, Kowaleski-Jones L, Smith KR, Zick CD. Moderate to vigorous physical activity and weight outcomes: does every minute count? Am J Health Promot. 2013;28(1):41-9.

8. Williamson DF, Madans J, Anda RF, Kleinman JC, Kahn HS, Byers T. Recreational physical activity and ten-year weight change in a US national cohort. Int J Obes Relat Metab Disord. 1993;17(5):279-86.

9. Di Pietro L, Dziura J, Blair SN. Estimated change in physical activity level (PAL) and prediction of 5-year weight change in men: the aerobics center longitudinal study. Int J Obes. 2004;28(12):1541-7.

10. Momenan AA, Delshad M, Mirmiran P, Ghanbarian A, Azizi F. Leisure time physical activity and its determinants among adults in Tehran: Tehran lipid and glucose study. Int J Prev Med. 2011;2(4):243-51.

11. van Sluiijs EM, Sharp SJ, Ambrosini GL, Cassidy A, Griffin SJ, Ekelund U. The independent prospective associations of activity intensity and dietary energy density with adiposity in young adolescents. Br J Nutr. 2016;115(5): 921-9.

12. Jalali-Farahani S, Amiri P, Chin YS. Are physical activity, sedentary behaviors and sleep duration associated with body mass index-for-age and healthrelated quality of life among high school boys and girls? Health Qual Life Outcomes. 2016;14(1):30.

13. Khashayar P, Kasaeian A, Heshmat R, Motlagh ME, Mahdavi Gorabi A, Noroozi $\mathrm{M}$, et al. Childhood overweight and obesity and associated factors in iranian children and adolescents: a multilevel analysis; the CASPIAN-IV study. Front Pediatr. 2018;6:393.

14. Vasconcellos F, Seabra A, Katzmarzyk PT, Kraemer-Aguiar LG, Bouskela E, Farinatti P. Physical activity in overweight and obese adolescents: systematic review of the effects on physical fitness components and cardiovascular risk factors. Sports Med. 2014;44(8):1139-52.

15. Mota J, Fidalgo F, Silva R, Ribeiro JC, Santos R, Carvalho J, et al. Relationships between physical activity, obesity and meal frequency in adolescents. Ann Hum Biol. 2008;35(1):1-10

16. Patrick K, Norman GJ, Calfas KJ, Sallis JF, Zabinski MF, Rupp J, et al. Diet, physical activity, and sedentary behaviors as risk factors for overweight in adolescence. Arch Pediatr Adolesc Med. 2004;158(4):385-90.

17. Kim Y, Lee J-M, Kim J, Dhurandhar E, Soliman G, Wehbi NK, et al. Longitudinal associations between body mass index, physical activity, and healthy dietary behaviors in adults: a parallel latent growth curve modeling approach. PLoS One. 2017;12(3):e0173986.

18. Wanner M, Martin BW, Autenrieth CS, Schaffner E, Meier F, Brombach C, et al. Associations between domains of physical activity, sitting time, and different measures of overweight and obesity. Prev Med Rep. 2016;3:177-84.

19. AACAP-American Academy of Child and Adolescent Psychiatry. Obesity in children and teens. 2016. Available online at:

20. Banihashemi S-AT, Amirkhani MA. Health literacy and the influencing factors: a study in five provinces of Iran; 2007.

21. Ejtahed H-S, Heshmat R, Motlagh ME, Hasani-Ranjbar S, Ziaodini H, Taheri M, et al. Association of parental obesity with cardiometabolic risk factors in their children: the CASPIAN-V study. PLoS One. 2018;13(4):e0193978.

22. Al-Isa AN, Akanji AO. Socio-demographic and health-related determinants of metabolic syndrome (MetS) among male Kuwaiti adolescents aged 10-19 years; 2013.

23. Baxi R, Vasan SK, Hansdak S, Samuel P, Jeyaseelan V, Geethanjali FS, et al. Parental determinants of metabolic syndrome among adolescent a sian Indians: a cross-sectional analysis of parent-offspring trios: 亚洲印度青少年 的代谢综合征是由父母双亲决定的: 一项有关父母-子女三者关系的横 断面分析. J Diabetes. 2016:8(4):494-501.

24. Khan RJ, Gebreab SY, Riestra P, Xu R, Davis SK. Parent-offspring association of metabolic syndrome in the Framingham heart study. Diabetol Metab Syndr. 2014;6(1):140. 
25. Hajian-Tilaki K, Heidari B. Childhood obesity, overweight, socio-demographic and life style determinants among preschool children in Babol, northern Iran. Iran J Public Health. 2013;42(11):1283.

26. Maddah M, Nikooyeh B. Factors associated with overweight in children in Rasht, Iran: gender, maternal education, skipping breakfast and parental obesity. Public Health Nutr. 2010;13(2):196-200.

27. Ottevaere C, Huybrechts I, Benser J, De Bourdeaudhuij I, Cuenca-Garcia M, Dallongeville J, et al. Clustering patterns of physical activity, sedentary and dietary behavior among European adolescents: the HELENA study. BMC Public Health. 2011;11(1):328.

28. Azizi F, Ghanbarian A, Momenan AA, Hadaegh F, Mirmiran P, Hedayati M, et al. Prevention of non-communicable disease in a population in nutrition transition: Tehran lipid and glucose study phase II. Trials. 2009;10(1):5.

29. Delshad M, Ghanbarian A, Ghaleh NR, Amirshekari G, Askari S, Azizi F. Reliability and validity of the modifiable activity questionnaire for an Iranian urban adolescent population. Int J Prev Med. 2015;6:3.

30. General USPHSOotS, Prevention NCfCD, Promotion H, Fitness PsCoP, Sports. Physical activity and health: a report of the Surgeon General: US Department of Health and Human Services, Centers for Disease Control and .... 1996.

31. Alberti $\mathrm{K}$, Eckel RH, Grundy SM, Zimmet PZ, Cleeman Jl, Donato KA, et al. Harmonizing the metabolic syndrome: a joint interim statement of the international diabetes federation task force on epidemiology and prevention; national heart, lung, and blood institute; American heart association; world heart federation; international atherosclerosis society; and international association for the study of obesity. Circulation. 2009;120(16): 1640-5

32. Delavari A, Forouzanfar MH, Alikhani S, Sharifian A, Kelishadi R. First nationwide study of the prevalence of the metabolic syndrome and optimal cutoff points of waist circumference in the Middle East: the national survey of risk factors for noncommunicable diseases of Iran. Diabetes Care. 2009;32(6):1092-7.

33. Azizi F, Hadaegh F, Khalili D, Esteghamati A, Hosseinpanah F, Delavari A, et al. Appropriate definition of metabolic syndrome among Iranian adults: report of the Iranian National Committee of Obesity. Arch Iran Med. 2010; 13(5):426.

34. Hu L, Bentler PM. Cutoff criteria for fit indexes in covariance structure analysis: conventional criteria versus new alternatives. Struct Equ Model Multidiscip J. 1999;6(1):1-55.

35. Kilani H, Al-Hazzaa H, Waly MI, Musaiger A. Lifestyle habits: diet, physical activity and sleep duration among Omani adolescents. Sultan Qaboos Univ Med J. 2013;13(4):510.

36. Al-Isa AN, Akanji AO. Socio-demographic and health-related determinants of metabolic syndrome (MetS) among male Kuwaiti adolescents aged 10-19 years. Health. 2013;5(04):720.

37. Ferreira I, Van Der Horst K, Wendel-Vos W, Kremers S, Van Lenthe FJ, Brug J. Environmental correlates of physical activity in youth-a review and update. Obes Rev. 2007:8(2):129-54.

38. Gustafson SL, Rhodes RE. Parental correlates of physical activity in children and early adolescents. Sports Med. 2006;36(1):79-97.

39. O'Donoghue G, Kennedy A, Puggina A, Aleksovska K, Buck C, Burns C, et al. Socio-economic determinants of physical activity across the life course: a "DEterminants of Dlet and Physical ACtivity" (DEDIPAC) umbrella literature review. PLoS One. 2018;13(1):e0190737.

40. Salahyan A, Rakhshanderou S, Ghaffari M, Mehrabi Y. Assessment of physical activity among adolescent girls in the west of Iran: status, limitations and solution. Iran J Public Health. 2018;47(6):914.

41. Bramsved R, Regber S, Novak D, Mehlig K, Lissner L, Mårild S. Parental education and family income affect birthweight, early longitudinal growth and body mass index development differently. Acta Paediatr. 2018;107(11): 1946-52.

42. Bahreynian M, Motlagh ME, Qorbani M, Heshmat R, Ardalan G, Kelishadi R. Prevalence of growth disorders in a nationally representative sample of Iranian adolescents according to socioeconomic status: the CASPIAN-II| study. Pediatr Neonatol. 2015;56(4):242-7.

43. Bahreynian M, Kelishadi R, Qorbani M, Motlagh ME, Kasaeian A, Ardalan G, et al. Weight disorders and anthropometric indices according to socioeconomic status of living place in Iranian children and adolescents: the CASPIAN-IV study. J Res Med Sci. 2015;20(5):440.

44. Rahmanian M, Kelishadi R, Qorbani M, Motlagh ME, Shafiee G, Aminaee T, et al. Dual burden of body weight among Iranian children and adolescents in 2003 and 2010: the CASPIAN-III study. Arch Med Sci. 2014;10(1):96.
45. Jalali-Farahani S, Amiri P, Abbasi B, Karimi M, Cheraghi L, Daneshpour MS, et al. Maternal characteristics and incidence of overweight/obesity in children: a 13-year follow-up study in an eastern Mediterranean population. Matern Child Health J. 2017;21(5):1211-20.

46. Te Velde SJ, De Bourdeaudhuij I, Thorsdottir I, Rasmussen M, Hagströmer M, Klepp K-I, et al. Patterns in sedentary and exercise behaviors and associations with overweight in 9-14-year-old boys and girls-a crosssectional study. BMC Public Health. 2007;7(1):16.

47. Manios Y, Yiannakouris N, Papoutsakis C, Moschonis G, Magkos F, Skender $\mathrm{K}$, et al. Behavioral and physiological indices related to BMI in a cohort of primary schoolchildren in Greece. Am J Hum Biol. 2004;16(6):639-47.

48. Salahshuri A, Sharifirad G, Hassanzadeh A, Mostafavi F. Physical activity patterns and its influencing factors among high school students of Izeh city: application of some constructs of health belief model. J Educ Health Promot. 2014:3:25

49. Saffari M, Amini N, Ardebili HE, Sanaeinasab H, Mahmoudi M, Piper CN. Educational intervention on health related lifestyle changes among Iranian adolescents. Iran J Public Health. 2013;42(2):172.

50. Shokrvash B, Majlessi F, Montazeri A, Nedjat S, Rahimi A, Djazayeri A, et al. Correlates of physical activity in adolescence: a study from a developing country. Glob Health Action. 2013;6(1):20327.

51. Ejtahed HS, Kelishadi R, Qorbani M, Motlagh ME, Hasani-Ranjbar S, Angoorani $\mathrm{P}$, et al. Utility of waist circumference-to-height ratio as a screening tool for generalized and central obesity among Iranian children and adolescents: the CASPIAN-V study. Pediatr Diabetes. 2019;20:530.

52. Parsons T, Manor O, Power C. Changes in diet and physical activity in the 1990s in a large British sample (1958 birth cohort). Eur J Clin Nutr. 2005; 59(1):49-56.

53. Picavet HSJ, Wendel-Vos GW, Vreeken HL, Schuit AJ, Verschuren WMM. How stable are physical activity habits among adults? The Doetinchem cohort study. Med Sci Sports Exerc. 2011;43(1):74-9.

54. Kelishadi R, Ardalan G, Gheiratmand R, Gouya MM, Razaghi EM, Delavari A, et al. Association of physical activity and dietary behaviours in relation to the body mass index in a national sample of Iranian children and adolescents: CASPIAN study. Bull World Health Organ. 2007;85:19-26.

55. Schwarzfischer P, Gruszfeld D, Socha P, Luque V, Closa-Monasterolo R, Rousseaux $\mathrm{D}$, et al. Longitudinal analysis of physical activity, sedentary behaviour and anthropometric measures from ages 6 to 11 years. Int J Behav Nutr Phys Act. 2018;15(1):126.

56. Chen H-H, Chen Y-L, Huang C-Y, Lee S-D, Chen S-C, Kuo C-H. Effects of oneyear swimming training on blood pressure and insulin sensitivity in mild hypertensive young patients. Chin J Phys. 2010;53(3):185-9.

57. Villa-Caballero L, Arredondo EM, Campbell N, Elder JP. Family history of diabetes, parental body mass index predict obesity in Latino children. Diabetes Educ. 2009;35(6):959-65.

58. Bouchard C, Tremblay A, Després J-P, Nadeau A, Lupien PJ, Thériault G, et al. The response to long-term overfeeding in identical twins. N Engl J Med. 1990;322(21):1477-82.

59. Silverman BL, Rizzo T, Green OC, Cho NH, Winter RJ, Ogata ES, et al. Longterm prospective evaluation of offspring of diabetic mothers. Diabetes. 1991;40(Supplement 2):121-5.

60. M-h J, Yang Y, Guo X-f, Y-x S. Association between child and adolescent obesity and parental weight status: a cross-sectional study from rural North China. J Int Med Res. 2013;41(4):1326-32.

61. Wardle J, Guthrie C, Sanderson S, Birch L, Plomin R. Food and activity preferences in children of lean and obese parents. Int J Obes. 2001;25(7): 971-7.

62. De Irala-Estevez J, Groth M, Johansson L, Oltersdorf U, Prättälä R, MartínezGonzález MA. A systematic review of socio-economic differences in food habits in Europe: consumption of fruit and vegetables. Eur J Clin Nutr. 2000; 54(9):706-14.

63. Stubbe JH, Boomsma DI, Vink JM, Cornes BK, Martin NG, Skytthe A, et al. Genetic influences on exercise participation in 37.051 twin pairs from seven countries. PLoS One. 2006;1(1):e22.

64. Jakicic JM, Rogers RJ, Davis KK, Collins KA. Role of physical activity and exercise in treating patients with overweight and obesity. Clin Chem. 2018; 64(1):99-107.

\section{Publisher's Note}

Springer Nature remains neutral with regard to jurisdictional claims in published maps and institutional affiliations. 